\title{
A High-Efficiency Protein Transduction System Demonstrating the Role of PKA in Long-Lasting Long-Term Potentiation
}

\author{
Masayuki Matsushita,, ${ }^{1}$ Kazuhito Tomizawa, ${ }^{1}$ Akiyoshi Moriwaki, ${ }^{1}$ Sheng-Tian Li, ${ }^{1}$ Hiroaki Terada, ${ }^{1,2}$ and \\ Hideki Matsui ${ }^{1}$ \\ ${ }^{1}$ First Department of Physiology and 2Department of Neurological Surgery, Okayama University Medical School, \\ Okayama 700-8558, Japan
}

\begin{abstract}
Proteins and peptides have been demonstrated to penetrate across the plasma membrane of eukaryotic cells by protein transduction domains. We show that protein transduction by 11 arginine $(11 R)$ is an efficient method of delivering proteins into the neurons of brain slices. Here, we demonstrate that PKA inhibitory peptide, fused with $11 R$ and nuclear localization signal, delivers the peptide exclusively into the nuclear compartment of neurons in brain slices. This inhibitory peptide blocked
\end{abstract}

A number of studies on the specific signal transduction pathways underlying the neuronal plasticity and electrophysiology of neurons, such as long-term potentiation (LTP) and long-term depression (LTD), have been performed using acute brain slices (Bliss and Collingridge, 1993; Bourne and Nicoll, 1993; Bear and Malenka, 1994; Steven and Sullivan, 1998). Because of its low efficiency, the expression of proteins by DNA transfection or viral infection is limited in acute brain slices. Therefore, a method of delivering physiologically active proteins and peptides directly into neurons and controlling subcellular localization of these substances within the neurons of brain slices would be advantageous in many experiments. Recently, a human immunodeficiency virus TAT protein transduction system has been shown to transduce biologically active proteins into cells (Nagahara et al., 1998). The TAT protein transduction system is capable of targeting all cell types and delivers the proteins in rapid and concentration-dependent fashion (Schwarze et al., 1999). Such rapid transduction is especially useful in studying neuronal tissues such as brain slices, which deteriorate quickly. However, the critical disadvantage of this method is its low transduction efficiency. Here, we show that protein transduction by means of the 11 arginines protein transduction domain $(11 R)$ is highly efficient in delivering proteins into the neurons of brain slices. Fusion of PKA inhibitory peptide (Kemp et al., 1988) with $11 R$ and nuclear localization signal (NLS) results in the delivery of the peptide exclusively into the nuclear compartment of neurons in brain slices. This inhibitory peptide blocked both cAMP responsive element-binding protein (CREB) phosphorylation and longlasting (L)-LTP induction. This technology introduces new op-

Received Feb. 13, 2001; revised May 17, 2001; accepted May 21, 2001.

This work was supported by a Grant-in-Aid for Scientific Research on Priority Areas (C) from the Ministry of Education, Science, Sports and Culture of Japan. We thank T. Takahashi for discussion and comments on this manuscript.

Correspondence should be addressed to Hideki Matsui, First Department of Physiology, Okayama University Medical School, 2-5-1 Shikata-cho, Okayama 7008558, Japan. E-mail: matsuihi@cc.okayama-u.ac.jp.

Copyright (ㄷ) 2001 Society for Neuroscience $\quad 0270-6474 / 01 / 216000-08 \$ 15.00 / 0$ both cAMP responsive element-binding protein phosphorylation and long-lasting long-term potentiation (LTP) induction, but not early LTP. These results highlight transduction of proteins and peptides into specific neuronal subcellular compartments in brain slices as a powerful tool for studying neuronal plasticity.

Key words: protein transduction; poly arginine; PKA; CREB; LTP; brain slice portunities to study the signal transduction systems that underlie neuronal plasticity.

\section{MATERIALS AND METHODS}

Construction of protein transduction domain-enhanced green fluorescence protein vectors. The following oligonucleotides (Amersham Pharmacia Biotech, Arlington Heights, IL) were synthesized. Oligo 11R-EGFP-S, $9 R$-EGFP-S, and $7 R$-EGFP-S correspond to the complements of the coding strand of enhanced green fluorescence protein (EGFP) and introduced 11, 9, and 7 arginines coding sequence and BamHI sites. Oligo EGFP-AS corresponds to the complements of the coding strand and introduced EcoRI site. Each mutant was amplified by PCR using the respective primers together with the oligonucleotides from $10 \mathrm{ng}$ EGFP cDNA (Clontech, Cambridge, UK) and the fragments subcloned into the BamHI and EcoRI sites of pET21a (+) (Novagen, Madison, WI) using a Ligation kit (TaKaRa, Tokyo, Japan), according to the manufacturer's instructions.

Expression and purification of recombinant proteins. BL21 (DE3) cells containing each expression plasmid were grown at $37^{\circ} \mathrm{C}$ to an OD600 of 0.8 . Isopropyl- $\beta$-D-thiogalactopyranoside was added to a final concentration of $0.1 \mathrm{~mm}$, and each culture was incubated for $12 \mathrm{hr}$ at $24^{\circ} \mathrm{C}$. Cells were harvested and resuspended in $100 \mathrm{ml}$ of lysis buffer containing $20 \mathrm{~mm}$ HEPES, pH8.0, $100 \mathrm{~mm} \mathrm{NaCl}, 8 \mathrm{M}$ urea, and $20 \mathrm{~mm}$ imidazol. Subsequently, the cells were sonicated, and the supernatants were recovered and applied to a column of Ni-NTA agarose (Invitrogen, San Diego, CA).

Synthesis of peptides. Peptides were synthesized by the Sigma Genosis Japan. The peptides were purified by preparative reversed-phase HPLC, were $>99.8 \%$ pure as analyzed by HPLC, and had the expected amino acid composition and mass spectra.

Protein kinase assays. PKA was obtained from Calbiochem (LaJolla, CA). Protein kinase assays were performed by previously described methods (Matsushita and Nairn, 1998). The assay mixture was placed on ice in a $1.5 \mathrm{ml}$ Eppendorf tube that contained $3 \mu \mathrm{l}$ of $10 \times$ kinase buffer [500 mM HEPES, $\mathrm{pH} 7.5,100 \mathrm{~mm} \mathrm{MgCl}_{2}$ ], $3 \mu \mathrm{l}$ of $1 \mathrm{~mm}$ synapsin I site 1 peptide, and each concentration of PKI peptides. Total reaction volume was $30 \mu \mathrm{l}$. Assay mixtures were preincubated for $30 \mathrm{~min}$, then started by adding $3 \mu \mathrm{l}$ of ATP mixture to make a total of $2.5 \mathrm{mCi}$ of $\left[\gamma^{-}{ }^{32} \mathrm{P}\right] \mathrm{ATP}$ per tube and $50 \mu \mathrm{M}$ ATP and allowed to progress in a $30^{\circ} \mathrm{C}$ water bath for 6 min. Reactions were stopped by adding $30 \mu \mathrm{l}$ of cold $30 \%$ acetic acid, and $50 \mu \mathrm{l}$ of each reaction mixture was applied to P81 Whatman phosphocellulose paper $(2 \times 2 \mathrm{~cm})$. The paper was washed four times with $250 \mathrm{ml}$ of $75 \mathrm{~mm}$ phosphoric acid for $10 \mathrm{~min}$ each time. Then, the paper was air-dried, and the radioactivity was counted (Cerenkov counting).

Transduction of protein into Cos-7, C2C12, U251-MG, PC12, and the 
primary culture of hippocampal neurons. Cos-7 cells and U251-MG were cultured on coverslip glasses with $10 \%$ FBS. The PC12 cells were plated on coverslips coated with laminin-poly-D-lysine and maintained in DMEM (Life Technologies, Gaithersburg, MD) with 10\% FBS plus 5\% HS. For differentiation, PC12 cells were treated with $100 \mathrm{ng} / \mathrm{ml} \mathrm{NGF}$ (Life Technologies) in DMEM (Life Technologies) with 0.5\% FBS. The primary culture of hippocampal neurons was prepared by means of the previously described modification (Yan et al., 2000). Briefly, hippocampal neurons were dissected from $18 \mathrm{~d}$ rat embryos (Japan SLC Inc., Shizuoka, Japan). The neurons were plated on coverslips coated with laminin-poly-D-lysine and maintained in serum-free Neurobasal medium (Life Technologies) with B27 supplements (Life Technologies). One micromolar protein transduction domain (PTD) proteins and peptides were incubated for $30 \mathrm{~min}$, and then the medium was changed and incubated for an additional $30 \mathrm{~min}$ to promote nuclear transport of the peptide. Subsequently, cells were fixed with $4 \%$ paraformaldehyde. FITC signals in neurons were examined using a Zeiss confocal microscope. For immunostaining, fixed neurons were stained by EGFP antibody (1:500; Clontech), GFAP antibody (1:200; Santa Cruz Biotechnology, Santa Cruz, CA), and MAP-2 antibody (1:5000; Sigma, St. Louis, MO).

Protein transduction in hippocampal slices. Hippocampal slices from 7-week-old Wistar rats were prepared as described previously (Lu et al., 1999a,b). Transversal slices (400 $\mu \mathrm{m}$ thick) were incubated with $1 \mu \mathrm{M}$ protein in artificial CSF (ACSF) saturated with $95 \% \mathrm{O}_{2}$ and $5 \% \mathrm{CO}_{2}$ for $30 \mathrm{~min}$ at $30^{\circ} \mathrm{C}$. Then, ACSF was changed to fresh ACSF without peptides and incubated an additional $30 \mathrm{~min}$ to promote the nuclear transport of the peptides. After washing with PBS three times, hippocampal slices were fixed with $4 \%$ paraformaldehyde. For MAP-2 staining, fixed slices were incubated with MAP-2 antibodies (1:5000; Sigma), synapsin antibody (1:200; Santa Cruz), EGFP antibody (1:500; Clontech), and GFAP antibody (1:200; Santa Cruz) for 24 hr. After primary antibodies were washed off, rhodamine-conjugated secondary antibodies (1:500; Chemicon, Temecula, CA) were incubated for 6 hr. Fluorescent images were examined using a Zeiss confocal microscope.

Analysis of phosphorylation in brain slices. Preparation of hippocampal slices and incubation with each peptide were performed as described. U0126 (10 $\mu \mathrm{M}$; Calbiochem) was incubated with hippocampal slices for $30 \mathrm{~min}$. Forskolin $(10 \mu \mathrm{M}$; Calbiochem $)$ and $100 \mu \mathrm{M}$ glutamate were added $30 \mathrm{~min}$ after replacement with fresh ACSF and incubated for 10 min. The reactions were stopped by adding boiled $0.1 \%$ SDS into the slices. Using SDS-PAGE, $10 \mu \mathrm{g}$ of protein were separated, and the gels were transferred to nitrocellulose filters and reacted with anti-phospho-CREB (S133) (New England Biolabs, Beverly, MA), anti-phospho-GluR1 (S845) (Upstate Biotechnology, Lake Placid, NY), and phospho-p44/42MAP kinase antibody (Thr202/Tyr204) (New England Biolabs).

Fluorescence measurement. To determine the fluorescence intensity of FITC-NLS-11R-PKI and NLS-11R-EGFP molecules in ACSF, pH 7.4, in cell free system, we used Aquacosmos Imaging System (Hamamatsu Photonics, Shizouka, Japan). The standard curve was determined from the intensity between FITC-NLS-11R-PKI and NLS-11R-EGFP excited at $488 \mathrm{~nm}$; the intensity showed a reasonable linear profile from $100 \mathrm{nM}$ to $5 \mu \mathrm{M}$. On the basis of our observation, the fluorescence intensity of FITC-NLS-11R-PKI is 1.4-fold brighter than NLS-11R-EGFP in ACSF at room temperature. To compare the nucleus concentration of FITCNLS-11R-PKI and NLS-11R-EGFP in slices, we used the digital images of brain slices acquired by a Zeiss confocal microscope. Analysis of signal intensity in each 50 nucleus of slices was performed using NIH imaging software. Then, the relative intensity of EGFP and FITC in slices was calculated from the value obtained from cell-free analysis. We assumed that the FITC and EGFP signals in slices would have the same fluorescence intensity ratio with cell-free measurement, because we measured the slices in the same $\mathrm{pH}$ and temperature with cell-free system.

Recording of field EPSP. The hippocampal slices were prepared from male C57BL6 mice aged 7-8 weeks. The slices (400 $\mu \mathrm{m}$ thick) were incubated in an interface recording chamber maintained at $28.5 \pm 0.5^{\circ} \mathrm{C}$ for at least $1.5 \mathrm{hr}$ before recording and were constantly submerged with gas-saturated ACSF at $1.5 \mathrm{ml} / \mathrm{min}$. The composition of the ACSF was as follows (in mM): $\mathrm{NaCl}, 124 ; \mathrm{KCl}, 4.4 ; \mathrm{CaCl}_{2}, 2.5 ; \mathrm{MgSO}_{4}, 1.3 ; \mathrm{NaH}_{2} \mathrm{PO}_{4}$, $1 ; \mathrm{NaHCO}_{3}, 26$; and glucose, 10 . The intensity of the stimulation was adjusted to produce an EPSP with a slope that was $\sim 50 \%$ of maximum. Test stimulation was delivered once per minute $(0.017 \mathrm{~Hz})$. For inducing LTP, either single or multiple trains of stimulation at $100 \mathrm{~Hz}$ for $1 \mathrm{sec}$ were delivered at the same intensity as the test stimulation. The hippocampal slices were incubated with each peptide for 45 min after
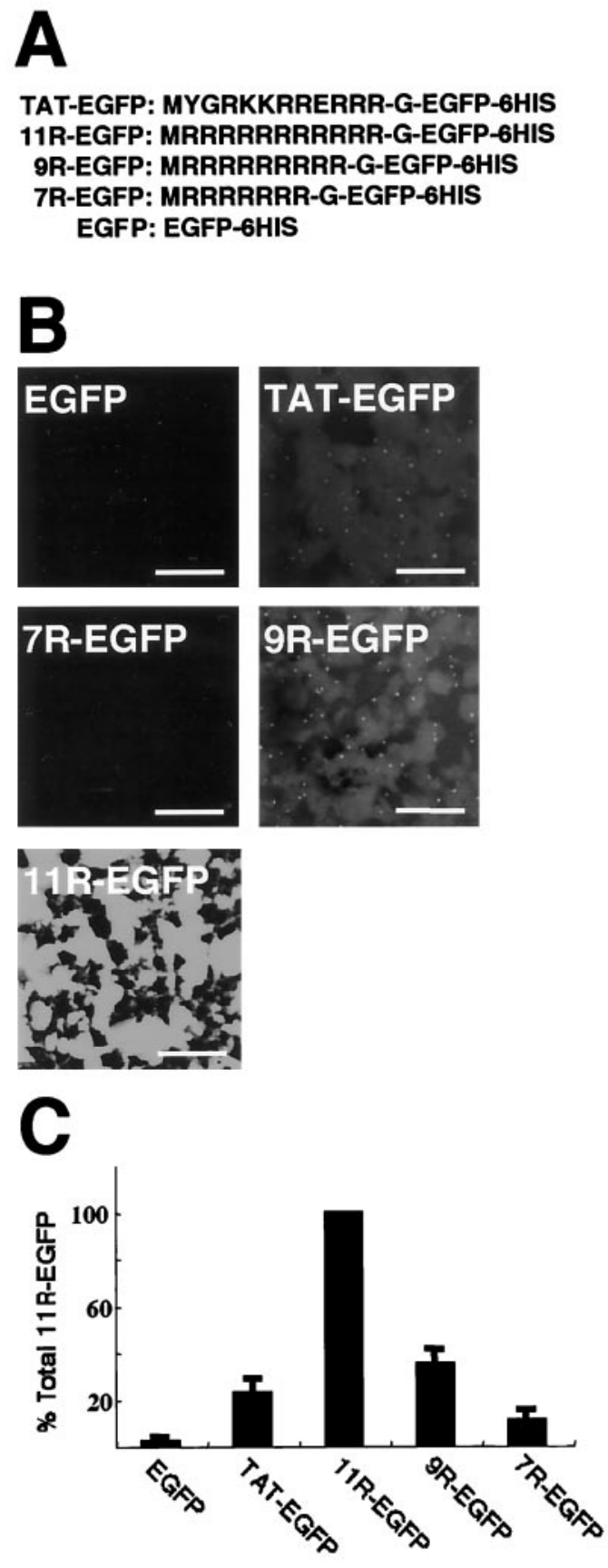

Figure 1. Transduction of a series of PTD-EGFP proteins into Cos-7 cells. $A$, Schematic representation of EGFP and PTD-EGFPs. A series of DNAs were amplified using PCR from cDNA encoding the EGFP (4). $B$, Analysis of protein transduction in Cos-7 cells by confocal microscopy. Cos-7 cells cultured on glass coverslips were incubated with $1 \mu \mathrm{M}$ EGFP, TAT-EGFP, $11 R$-EGFP, $9 R$-EGFP, and $7 R$-EGFP. After $30 \mathrm{~min}$, cells were washed three times and incubated another $30 \mathrm{~min}$ and then analyzed by confocal microscopy. Laser power was identical within each experiment. Scale bar, $100 \mu \mathrm{m}$. $C$, The intracellular presence of the EGFP was analyzed by Western blotting using GFP monoclonal antibody; then, signals were analyzed by NIH Image $(n=3)$.

stabilization of basal EPSPs. Then the slices were stimulated at $30 \mathrm{~min}$ after perfusion of ACSF without peptide. Data are shown as mean $( \pm$ SEM) percentage of baseline EPSP slope. Statistical significance was evaluated by one-way ANOVA followed by Student's $t$ test. The slice preparation for field recording has been described in detail previously (Lu et al., 1999a,b). 

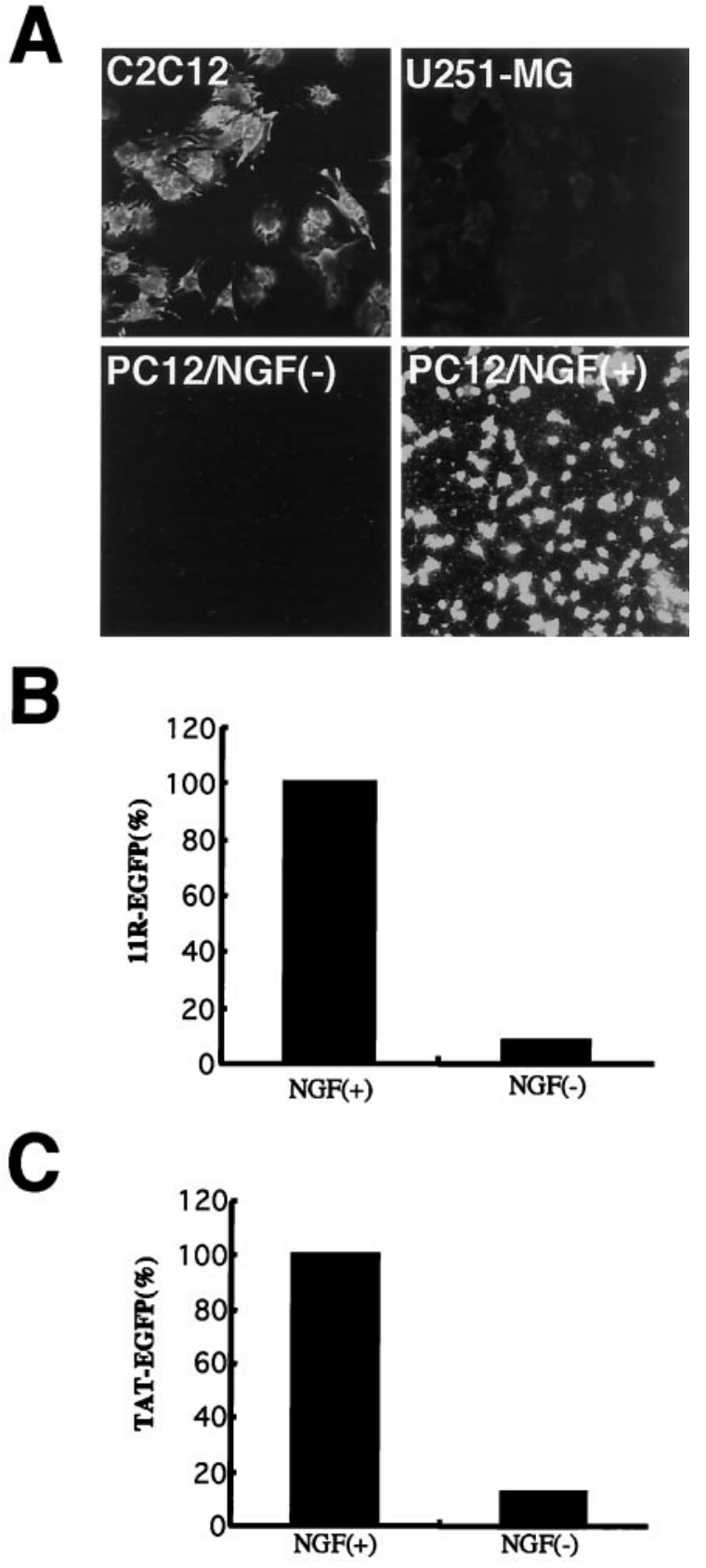

Figure 2. Cell type specificity of $11 R$ protein transduction domain. $A$, $11 R$-EGFP protein $(1 \mu \mathrm{M})$ was incubated with cells for $30 \mathrm{~min}$, after which the medium was changed, incubated for another $30 \mathrm{~min}$, and washed three times with PBS. The cells were analyzed by confocal microscopy. Laser power was identical within each experiment. PC12 cells were treated with $100 \mathrm{ng} / \mathrm{ml} \mathrm{NGF}$ (Life Technologies) in DMEM (Life Technologies) with $0.5 \%$ FBS for $2 \mathrm{~d}$. The intracellular presence of the $11 R$-EGFP $(B)$ and TAT-EGFP $(C)$ in PC12 cells was analyzed by Western blotting using GFP monoclonal antibody; then, signals were analyzed by NIH Image $(n=3)$. The data shown are the average of three experiments. Three independent experiments gave similar results.

\section{RESULTS}

\section{Efficient protein delivery by 11 arginines protein transduction domain}

We developed a novel, high-efficiency PTD that was based on the TAT sequence (Frankel and Pabo, 1988; Green and Loewenstein, 1988), which has six arginines and two lysines in the PTD se-

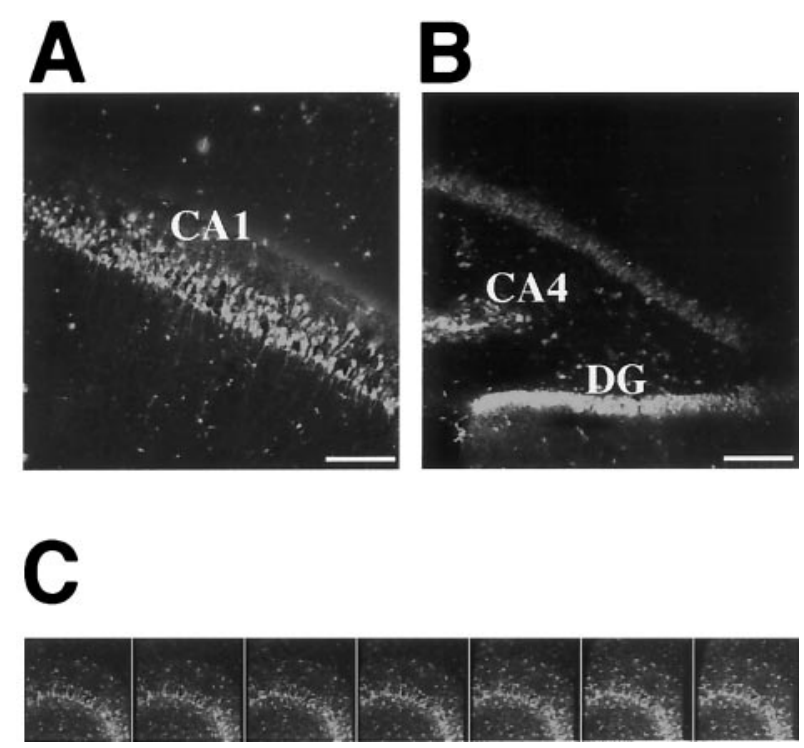

Figure 3. Transduction of $11 R$-EGFP into a hippocampal brain slice. Protein $(1 \mu \mathrm{M})$ was incubated with the brain slice for $30 \mathrm{~min}$, after which the medium was changed, incubated for another $30 \mathrm{~min}$, and washed three times with PBS. The slices were analyzed by confocal microscopy. 11REGFP was transduced in the neurons of hippocampus. EGFP signals in neurons were examined using a Zeiss confocal microscope. 11R-EGFP was transduced into the neurons in the CA1 region $(A)$, and CA4 and dentate gyrus $(D G)(B)$. Scale bars, $100 \mu \mathrm{m}$. $C$, The images are multiple optical $12 \mu \mathrm{m}$ step sections spanning the $Z$-dimension of laser scans of the area CA2-CA3 of hippocampal slice.

quence (Fig. 1A). On the basis of the amino acid sequence of the PTD of other proteins, we speculated that poly-arginine was the most important factor for membrane penetration (Derossi et al., 1996; Elliott and O'Hare, 1997; Lindgren et al., 2000; Rothbard et al., 2000; Schwarze and Dowdy, 2000). Therefore, we constructed a bacteria expression vector consisting of 7 arginines $(7 R), 9$ arginines $(9 R)$, and 11 arginines $(11 R)$ followed by EGFP (Fig. $1 A)$. Recombinant proteins were purified under denatured conditions and dialyzed against PBS as described previously (Nagahara et al., 1998). To analyze the transduction ability of argininebased PTD-EGFP proteins, we incubated Cos-7 cells with $1 \mu \mathrm{M}$ protein for $30 \mathrm{~min}$ and then analyzed by confocal laser microscopy and immunoblotting. Without the PTD domain, EGFP evinced no fluorescent signal in the cells. The original TATEGFP showed the signal in both the cytoplasm and nucleus of Cos-7 cells. The $11 R$-EGFP showed a much stronger signal than the original TAT-EGFP in all regions of the cells. Incubation with $11 R$-EGFP, 9R-EGFP, and 7R-EGFP demonstrated that the arginine length is a critical factor in determining transduction efficiency in culture cells (Fig. $1 B$ ). Immunoblotting of EGFP showed that the efficiency of $11 R$ in delivering the EGFP protein in Cos-7 cells was at least four times greater than that of the original TAT domain. Reduction of the arginine length reduced the signal intensity of EGFP in immunoblotting (Fig. 1C).

\section{Transduction specificity of $11 R$ domain in different cells}

Previous study demonstrated that TAT transduction domain delivered the fusion protein into all tissues such as liver, muscle, kidney, spleen, and brain (Schwarze et al., 1999). To examine the transduction specificity of $11 R$ domain in different cell lines, $11 R$-EGFP was incubated with $\mathrm{C} 2 \mathrm{C} 12$ skeletal muscle cell line, U251-MG glial cell line, and PC12 pheochromocytoma cell line. 

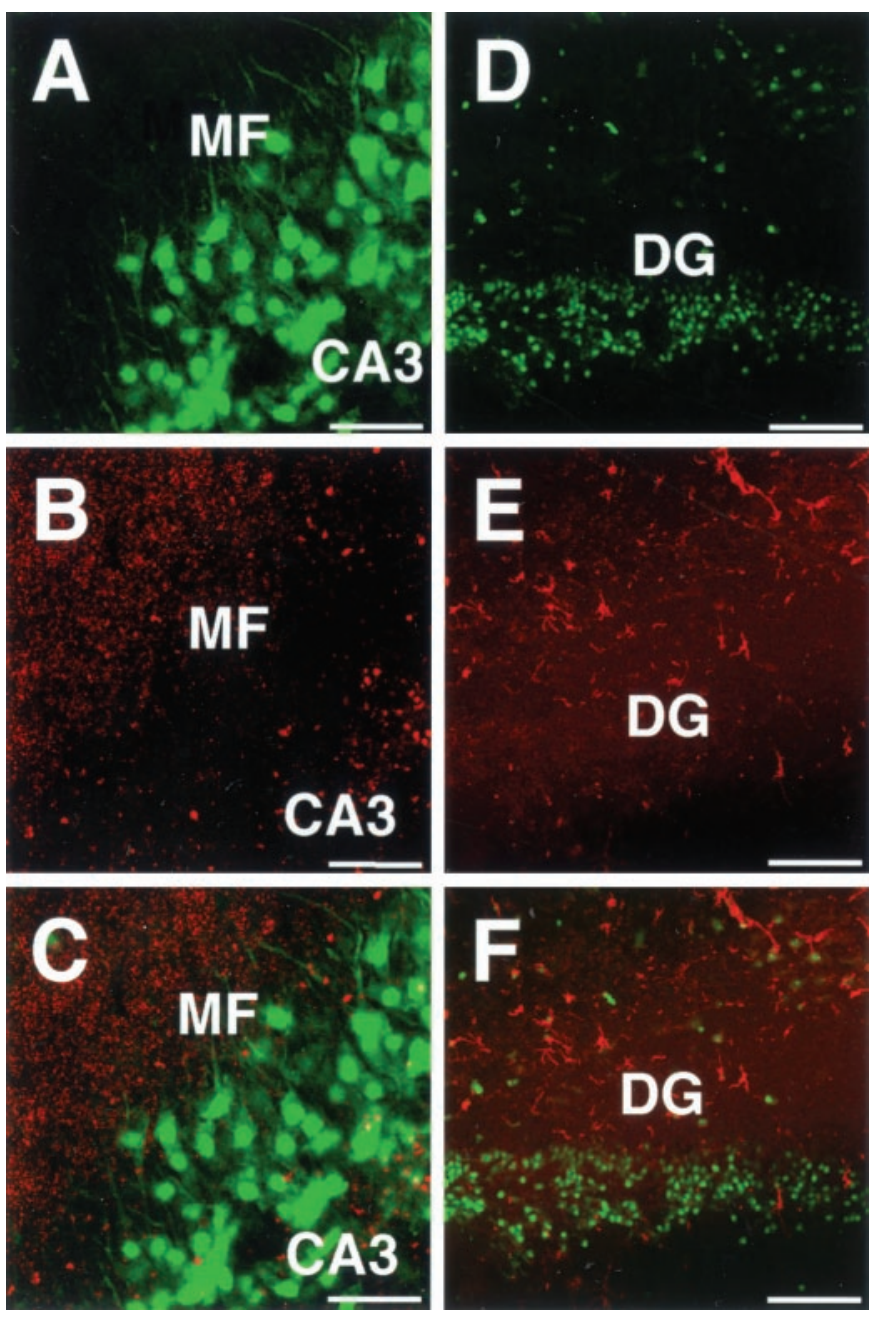

Figure 4. Distribution of $11 R$-EGFP in a hippocampal brain slice. $A-C$, Double staining with EGFP (green) and rhodamine-conjugated second antibody against synapsin antibody (red). $D-F$, Double staining with EGFP (green) and rhodamine-conjugated second antibody against GFAP antibody (red). $M F$, Mossy fiber; $D G$, dentate gyrus. Scale bars: $A-C, 50$ $\mu \mathrm{m} ; D-F, 200 \mu \mathrm{m}$.

$11 R$-EGFP transduced efficiently into $\mathrm{C} 2 \mathrm{C} 12$; however, weak signals were observed in U251-MG glia cell line (Fig. $2 A$ ). We found that $11 R$ domain did not deliver the EGFP into the PC 12 cells (Fig. 2A) These results raise the possibility that $11 R$ domain has the cell type specificity for protein transduction into cells. To test this hypothesis, we induced PC12 cell differentiation by NGF for $2 \mathrm{~d}$; then we added $1 \mu \mathrm{M} 11 R$-EGFP in cell medium. In contrast to nondifferentiated PC12, differentiated cells acquired high $11 R$ transduction efficiency (Fig. 2A,B). TAT protein transduction domain also showed the same transduction specificity for the differentiated PC12 (Fig. 2C). A recent study suggests that TAT transduction is endocytosis-dependent and mediated by the heparan sulfate proteoglycan receptor (Tyagi et al., 2001). NGF induces the heparan sulfate proteoglycan in PC12 cells (KatohSemba et al., 1990). These results showed that $11 R$ domain indeed had cell type specificity to deliver the protein.

\section{Transduction of EGFP into the neurons of acute hippocampal slices}

Subsequently, we determined whether the $11 R$ domain would deliver the protein to the neurons in a brain slice. Incubation of

\section{A}
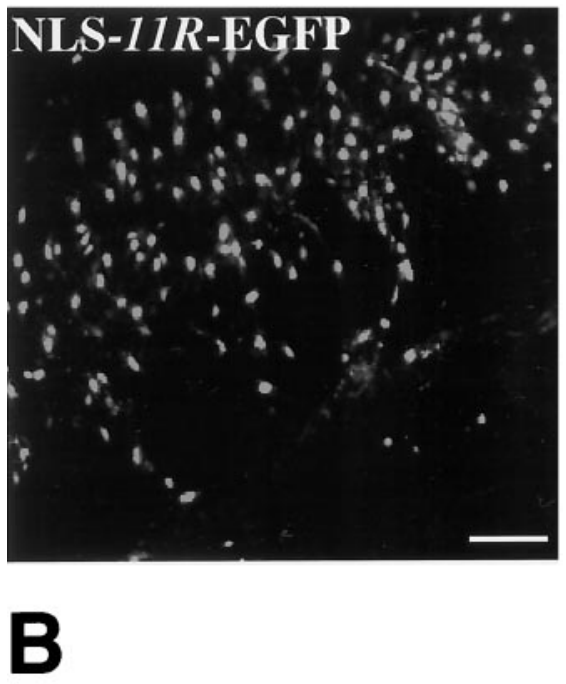

(11R - PKI)

FITC-11R-G-FIASGRTGRRNAI

\section{(NLS-11R - PKI)}

FITC-PKKKRKV-11R-G-FIASGRTGRRNAI
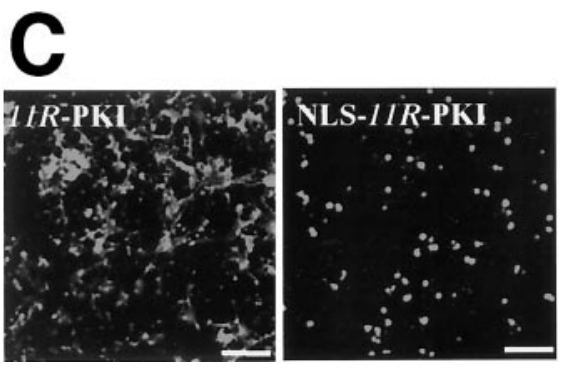

Figure 5. Analysis of subcellular localization of NLS-11R-EGFP, FITC$11 R$-PKI, and FITC-NLS-11R-PKI in a hippocampal slice and primary culture neurons. $A$, Transduction of NLS-11R-EGFP into a hippocampal brain slice. Protein $(1 \mu \mathrm{M})$ was incubated with the brain slice for $30 \mathrm{~min}$, after which the medium was changed and incubated for another $30 \mathrm{~min}$. The CA1 region of slices was analyzed by confocal microscopy. $B$, Schematic representation of synthesized PKA inhibitor peptides. $C$, Subcellular localization of FITC-11R-PKI and FITC-NLS-11R-PKI in $10 \mathrm{~d}$ primary culture neurons. Primary culture neurons were incubated with each peptide $(1 \mu \mathrm{M})$ for $30 \mathrm{~min}$, after which the medium was changed and incubated for another $30 \mathrm{~min}$. Culture cells were fixed by $4 \%$ paraformaldehyde and then analyzed by confocal microscopy. Scale bars, $100 \mu \mathrm{m}$.

$11 R$-EGFP with brain slices for $30 \mathrm{~min}$ enabled delivery of a high level of EGFP into the hippocampal neurons of the brain slice. Examination of the slices by confocal laser microscope demonstrated that $11 R$-EGFP was effectively introduced into the pyramidal and granule cells in the hippocampus (Fig. $3 A, B$ ). $11 R$ EGFP exhibited a diffuse fluorescent signal throughout the cytoplasm, nucleus, and dendrites. To examine how deeply into the tissue the $11 R$ fusion protein can penetrate hippocampal slices, we collected serial optical sections of $12 \mu \mathrm{m}$ steps along the $Z$-dimension by confocal laser microscope. Each section in different depths from the slice surface showed essentially the same fluorescence intensity (Fig. $3 C$ ). Without the 11R, EGFP produced no green signal in the hippocampus (data not shown). To examine the subcellular localization of transduction protein in 


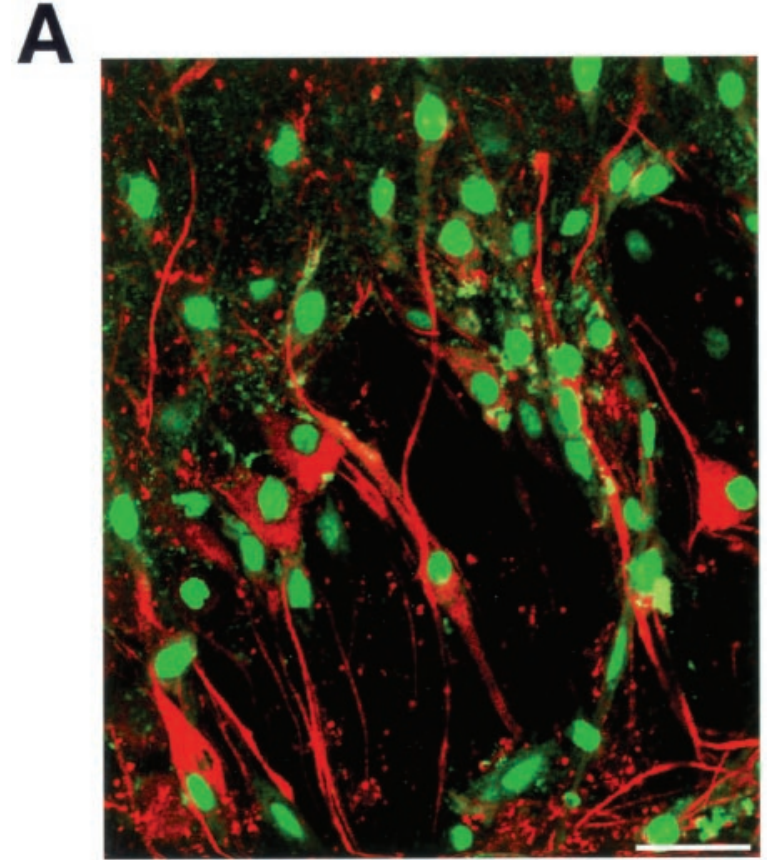

B

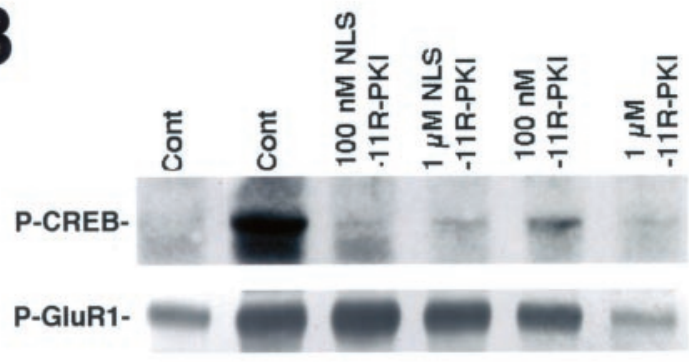

Actin-

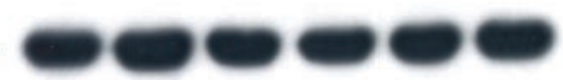

Forsk
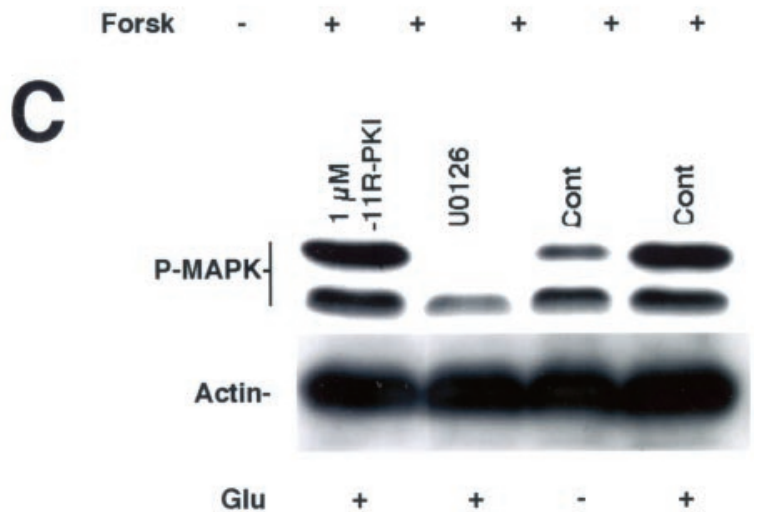

Figure 6. Inhibition of PKA activity in brain slices. $A$, Transduction of FITC-NLS-11R-PKI into a hippocampal brain slice. Peptide $(1 \mu \mathrm{M})$ was incubated with the brain slice for $30 \mathrm{~min}$, after which the medium was changed, incubated for another $30 \mathrm{~min}$, washed three times with PBS, and then fixed with $4 \%$ paraformaldehyde. The fixed slices were stained with MAP-2 monoclonal antibody. FITC signals in neurons of the brain slices were examined using a Zeiss confocal microscope. FITC-NLS-11R-PKI was localized in the nucleus. Pyramidal neurons in CA1 were detected by MAP-2 antibody (red). The nuclei of pyramidal neurons showed the green FITC-NLS-11R-PKI signal. Scale bar, $50 \mu \mathrm{m}$. B, Reduced phosphorylation of CREB at serine 133 by $11 R$-PKI and NLS-11R-PKI. Hippocampal brain slices were incubated at the indicated peptide concentration and control (absence of peptide) for $1 \mathrm{hr}$, after which the ACSF was changed neurons, we used the immunostaining studies of synapsin, a protein present at presynapse (Greengard et al., 1993). Using immunostaining of synapsin, presynapses of mossy fibers were stained as small red dots (Fig. 4B). In contrast, green EGFP signal was not observed in presynapses of mossy fibers (Fig. $4 A$ ). Double labeling image did not show any colocalization with EGFP and synapsin in mossy fibers (Fig. $4 C$ ). To determine whether protein could transduce glia cells in brain slices, slices were stained with antibody against a glia maker, GFAP. EGFP strongly transduced into the granule cells of the dentate gyrus (Fig. $4 D$ ), however EGFP was not observed in GFAP-positive cells (Fig. $4 E, F$ ). These data strongly support the idea that $11 R$ delivered the protein into the neurons but could not deliver into the glia cells in acute brain slices.

\section{Delivering the peptides and protein into the neuronal nucleus}

To deliver the protein into the neuronal nucleus, we expressed recombinant EGFP fused with $11 R$ and the SV40 NLS. Then, we examined whether the NLS-11R would deliver EGFP to the nucleus of neurons in a brain slice. Examination of the brain slices by confocal laser microscope demonstrated that EGFP was effectively introduced into the nucleus of pyramidal cells of CA1 area in the hippocampus (Fig. 5A). To investigate cAMPdependent protein kinase (PKA) function in the neuronal nucleus, we synthesized two peptides; PKA inhibitory peptide (PKI 10-22 amide) fused with $11 R$ and the SV40 NLS (Fig. 5B). To evaluate the specificity of these peptides, IC50 for PKA were measured by protein kinase assay using synapsin site I peptide (Matsushita and Nairn, 1998). IC IC $_{50}$ of FITC-11R-PKI for PKA was at $92 \mathrm{nM}$, and FITC-NLS-11R-PKI for PKA was at $103 \mathrm{~nm}$. Each synthesized peptide was added to hippocampal primary neurons for $30 \mathrm{~min}$, after which the medium was changed and incubated for another $30 \mathrm{~min}$ to promote nuclear transport. $11 R$-PKI exhibited a diff use fluorescent signal throughout the cytoplasm, nucleus, and cellular processes, whereas the NLS$11 R$-PKI was localized specifically in the nucleus (Fig. $5 C$ ).

Next, we determined whether the NLS-11R would deliver PKI peptide to the nucleus of neurons in a brain slice. Incubation of NLS-11R-PKI with brain slices for 30 min enabled delivery of a high level of peptides into the neurons of brain slices. Examination of the brain slices by confocal laser microscope demonstrated that NLS-11R-PKI peptide was effectively introduced into the nucleus of pyramidal cells in the hippocampus (Fig. 6A). Double staining of MAP-2 and NLS-11R-PKI in the CA1 region showed that the inhibitory peptide was localized exclusively in the nuclear compartment of pyramidal neurons (Fig. $6 A$ ).

To determine whether the NLS-11R-PKI peptide was physiologically active as a PKA inhibitor after transduction into brain slices, we examined the phosphorylation of Ser133 of the CREB

\section{$\leftarrow$}

and incubated $30 \mathrm{~min}$. The slices were stimulated by $10 \mu \mathrm{M}$ of forskolin (Forsk) for $10 \mathrm{~min}$. The reactions were immediately stopped by adding $0.1 \%$ SDS into the slices. Then, samples were analyzed by Western blotting using phospho-Ser133 CREB specific antibody, phospho-Ser 845 GluR1 antibody, and actin antibody $(n=3)$. $C, 11 R$-PKI did not inhibit the MAP kinase cascade. Hippocampal brain slices were incubated at the indicated peptide concentration, control (Cont; absence of peptide), and $10 \mu \mathrm{M}$ U0126 for $30 \mathrm{~min}$, after which the ACSF was changed and incubated $30 \mathrm{~min}$. The slices were stimulated by $100 \mu \mathrm{M}$ glutamate $(\mathrm{Glu})$ for $10 \mathrm{~min}$. Samples were analyzed by Western blotting using phosphop42/44 MAP kinase antibody and actin antibody $(n=3)$. Three independent experiments gave similar results. 
Table 1. Comparison of paired-pulse facilitation (PPF) and field EPSP (fEPSP) slope in NLS-11R-GFP- and NLS-11R-PKI-treated slices and controls

\begin{tabular}{lllll} 
& \multicolumn{2}{l}{ ISI } & fEPSP slope \\
\cline { 2 - 4 } & $50 \mathrm{msec}$ & $75 \mathrm{msec}$ & $100 \mathrm{msec}$ & \\
\hline Control $(n=6)$ & $149 \pm 9$ & $141 \pm 5$ & $133 \pm 6$ & $101 \pm 3$ \\
NLS-11R-GFP $(n=6)$ & $151 \pm 7$ & $144 \pm 8$ & $135 \pm 6$ & $102 \pm 5$ \\
NLS-11R-PKI $(n=6)$ & $146 \pm 9$ & $142 \pm 7$ & $136 \pm 8(\%)$ & $97 \pm 5(\%)$
\end{tabular}

Hippocampal slices were incubated with NLS-11R-GFP or NLS-11R-PKI for 30 min and then were perfused with ACSF. After 30 min, PPF and fEPSP slopes were measured. Data of PPF are presented as mean \pm SEM of the facilitation of the second response relative to the first response. PPF was tested with 50, 75, and 100 msec interstimulus interval (ISI).

and Ser845 of the GluR1. It has been show that Ser133 of the CREB was phosphorylated by multiple protein kinases such as PKA, calmodulin-dependent protein kinase IV, extracellular signal-regulated protein kinases (ERK), and Rsk2 in the nucleus (Gonzalez and Montminy, 1989; Bito et al., 1996; Xing et al., 1996). A recent study showed that Ser845 of the GluR1 was phosphorylated specifically by PKA in the postsynaptic regions (Kameyama et al., 1998). Phospho-specific antibodies for each site were used to examine the change of phosphorylation level of each site through PKA inhibition by the transduction of inhibitory peptides in brain slices. Even $100 \mathrm{~nm}$ NLS-11R-PKI almost completely blocked the phosphorylation of CREB by PKA, which was stimulated by forskolin. Phosphorylation of CREB was inhibited partially by $100 \mathrm{~nm} 11 R$-PKI and completely by $1 \mu \mathrm{M}$. In contrast, NLS-11R-PKI did not reduce the Ser 845 of the GluR1, even at a concentration of $1 \mu \mathrm{M}$. However, $11 R$-PKI significantly reduced the phosphorylation of the GluR1 at a concentration of $1 \mu \mathrm{M}$ (Fig. 6B). These results suggested that NLS-11R-PKI specifically blocked the PKA activity in the nucleus, but not in the synaptic regions. We next determined whether mitogen-activated protein kinase $(\mathrm{MAPK}) /(\mathrm{ERK})$ kinase $(\mathrm{MEK})$ was inhibited when the slices were stimulated by glutamate in the presence of the $11 R$-PKI and U0126, a specific inhibitor of MEK1/2. Stimulation of metabotropic glutamate receptors leads to an activation of the MAPK and ERK (English and Sweatt, 1996; Ferraguti et al., 1999). As shown in Figure $6 C$, application of $10 \mu \mathrm{M} U 0126$ reduced the phosphorylation of $\mathrm{p} 42$ and $\mathrm{p} 44$ MAPK. In contrast, $11 R$-PKI had no effect on the phosphorylation of MAPK by MEK. These data showed that PKI peptides were specific for PKA but not for MAP kinase cascade.

NLS-11R-PKI blocks L-LTP induction, but not early LTP LTP is activity-dependent strengthening of synaptic efficacy; early (E)-LTP can last for $1 \mathrm{hr}$, and L-LTP can last $>3 \mathrm{hr}$, depending on the stimulation pattern (Frey et al., 1993; Huang and Kandel, 1994). Phosphorylation of CREB by PKA is thought to be a critical step for induction of L-LTP in the CA1 region of the hippocampus (Frey et al., 1993; Huang and Kandel, 1994; Abel et al., 1997; Impey et al., 1998). PKA acts in multiple subcellular compartments and phosphorylates different substrates such as AMPA receptor, inhibitor-1, and CREB in neurons (Gonzalez and Montminy, 1989; Shenolikar and Nairn, 1991; Kameyama et al., 1998). Conventional pharmacological studies have failed to answer the critical questions of whether PKA phosphorylates the substrates for induction of L-LTP in the nucleus or in the synaptic regions in neurons.

We examined the effect of NLS-11R-PKI on E-LTP and
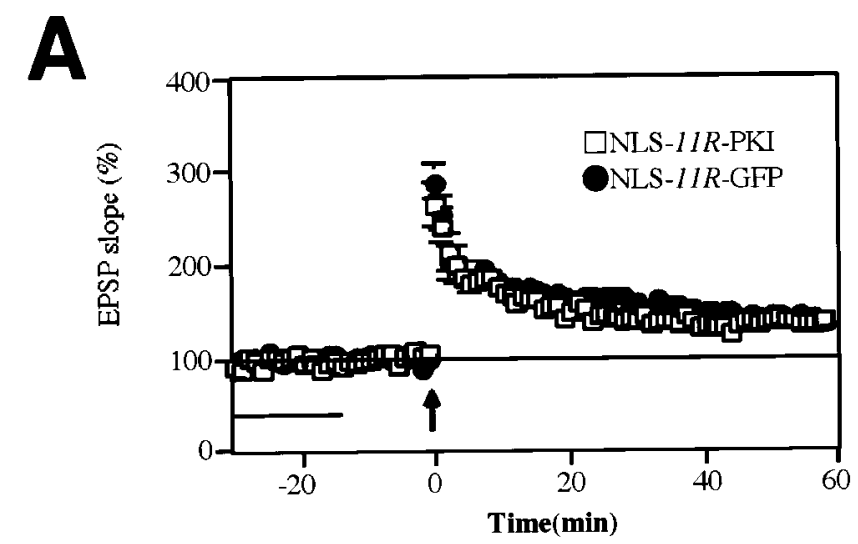

B
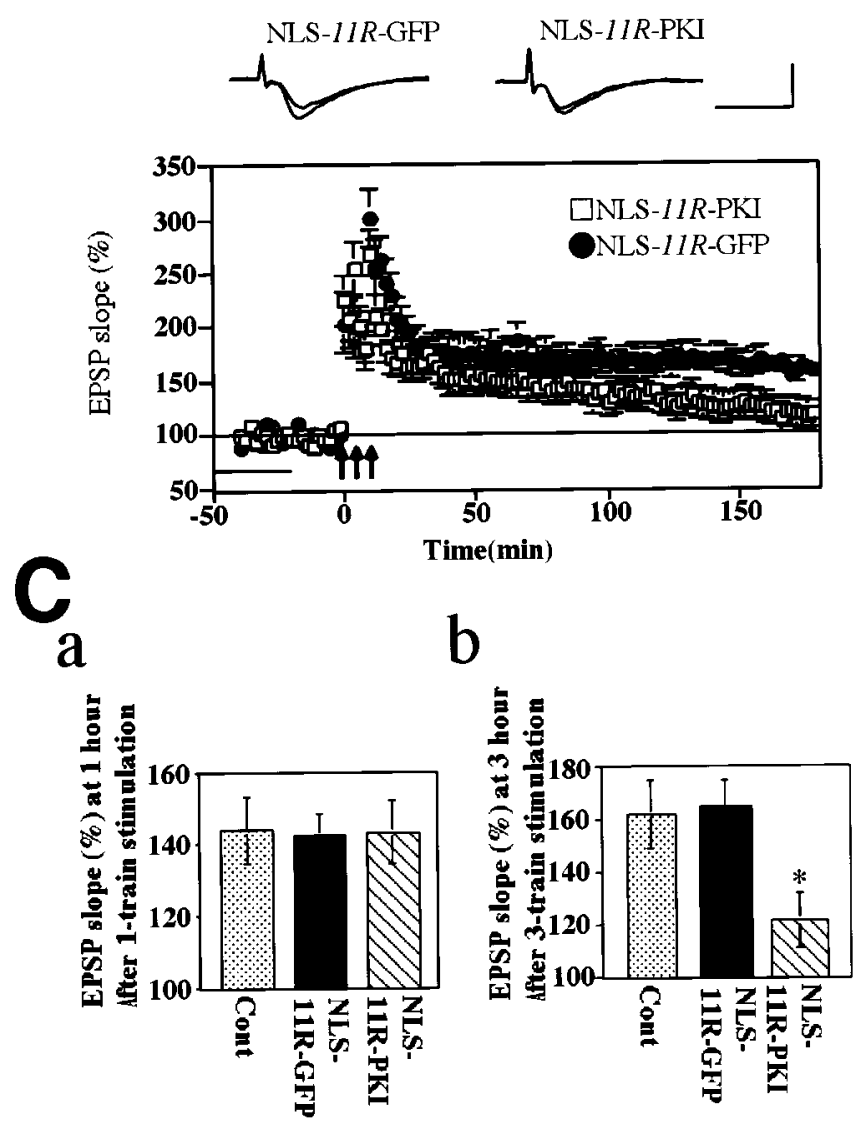

Figure 7. NLS-11R-PKI peptides inhibited the L-LTP induction, but not that of E-LTP. $A$, NLS-11R-PKI did not block E-LTP induced by one train of $100 \mathrm{~Hz}$ for $1 \mathrm{sec}$ tetanization (arrow). B, NLS-11R-PKI significantly inhibited L-LTP induced by three trains of $100 \mathrm{~Hz}$ for $1 \mathrm{sec}$ tetanization (arrows). In contrast, NLS-11R-GFP had no effect on the L-LTP. Insets, Representative field EPSPs before and $3 \mathrm{hr}$ after tetanic stimulations are shown. Calibration: $10 \mathrm{msec}, 2 \mathrm{mV}$. C, Comparisons of EPSPs slope $1 \mathrm{hr}(a)$ and $3 \mathrm{hr}(b)$ after tetanic stimulation for induction of either E-LTP or L-LTP, respectively. ${ }^{*} p<0.01$ compared with the control slices.

L-LTP in the CA1 region of the mouse hippocampus. NLS-11RPKI did not impair basic electrophysiological activity such as basal EPSP and paired pulse facilitation (Table 1). Moreover, NLS-11R-PKI peptide did not block the E-LTP elicited by a single train in brain slices (Fig. 7A). EPSP amplitude in NLS$11 R$-PKI peptide-incubated slices was the same as that of the 
control and NLS-11R-EGFP-treated slices. We also determined the relative fluorescence intensity between FITC-11R-NLS-PKI and NLS-11R-EGFP signals in these slices. The fluorescence signals of both molecules were of the same intensity in the nucleus of these slices as described as Materials and Methods. Therefore, we assumed the concentration of NLS-11R-PKI and NLS-11REGFP in the nucleus was almost the same in these slices. Three trains of $100 \mathrm{~Hz}$ for $1 \mathrm{sec}$ stimulation induced stable long-lasting LTP (the EPSP slope was $164 \pm 12.6 \%$ of baseline $3 \mathrm{hr}$ after the end of tetanization; $n=6$ ) (Fig. $7 B$ ). NLS-11R-EGFP delivered the EGFP into the nucleus of hippocampus (Fig. $5 A$ ) and had no effect on L-LTP $(158 \pm 10.6 \% ; n=6)$. In contrast, NLS-11R-PKI significantly inhibited L-LTP $3 \mathrm{hr}$ after stimulation $(121 \pm 11 \%$; $n=6 ; F_{(1,30)}=31.56 ; p<0.01$ compared with control) (Figure $7 B, C)$. These data suggest that inhibition of PKA activity in the nucleus was sufficient to prevent the induction of L-LTP in the CA1 of the hippocampus.

\section{DISCUSSION}

It has been demonstrated that proteins and peptides penetrate across the plasma membrane of eukaryotic cells by means of protein transduction domains (Lindgren et al., 2000; Schwarze and Dowdy, 2000). Protein transduction by $11 R$ was highly efficient in delivering proteins into culture cells and brain slices, especially into the neurons. The mechanism of plasma membrane transduction by $11 R$ is still to be elucidated; however, recent study of TAT transduction system suggests that transduction is mediated by endocytosis mediated by heparan sulfate proteoglycan receptors. In contrast, oligopeptide penetratin derived from the homeodomain of Antennapedia has shown to translocate across pure lipid bilayers (Thoren et al., 2000). 11R domain requires the differentiation by NGF treatment for plasma membrane transduction in PC12 cells (Fig. 2). The results support the idea that the uptake mechanism involves receptor or transporter-dependent pathway. Therefore, expression level of receptors for $11 R$ on the cell membrane might be a critical factor for cell type specificity of protein transduction.

The results of our studies using brain slices are sufficient to show how effective this system is for analyzing the molecular mechanism in neurons. Previous studies suggest that PKA plays a key role in induction of L-LTP through the phosphorylation of CREB in the hippocampus (Abel et al., 1997; Impey et al., 1998). However, it is difficult to show whether PKA acts in the nucleus or in other compartments of the neurons during the induction of L-LTP. NLS-11R-PKI showed that inhibition of PKA in the nucleus decreased the phosphorylation of Ser133-CREB and blocked L-LTP induction. The data indicated that for induction of L-LTP, active PKA translocation into the nucleus is essential. These results agreed very well with the data from hippocampusspecific PKA regulatory subunit transgenic mice (Abel et al., 1997). In this transgenic experiment, however, PKA activity was inhibited both at the synapses and in the cytoplasm by overexpression of the regulatory subunit of PKA. Our data define the role of PKA in the nucleus during L-LTP induction in the CA1 region.

Genetic and pharmacological studies have provided important information regarding the molecular function of neural physiology. In addition to these methods, the protein transduction system provides many advantages for analysis of molecular function and the electrophysiology of neurons as described in this report. To carry the molecular analysis of signal transduction and electrophysiology in neurons further, it will be necessary to develop the delivery of proteins, compounds, antisense oligonucleotides, etc., to neuronal subcellular compartments such as the nucleus, postsynaptic terminal, and presynaptic terminal in brain slices.

\section{REFERENCES}

Abel T, Nguyen PV, Barad M, Deuel TA, Kandel ER, Bourtchouladze R (1997) Genetic demonstration of a role for PKA in late phase of LTP and hippocampus-based long-term memory. Cell 88:615-626.

Bear MF, Malenka RC (1994) Synaptic plasticity: LTP and LTD. Curr Opin Neurobiol 4:389-399.

Bito H, Deisseroth K, Tsien RW (1996) CREB phosphorylation and dephosphorylation: $\mathrm{a} \mathrm{Ca}^{2+}$ and stimulus duration-dependent switch for hippocampal gene expression. Cell 87:1203-1214.

Bliss TV, Collingridge GL (1993) A synaptic model of memory: longterm potentiation in the hippocampus. Nature 361:31-39.

Bourne HR, Nicoll R (1993) Molecular machines integrate coincident synaptic signal. Cell 72:65-75.

Derossi D, Calvet S, Trembleau A, Brunissen A, Chassaing G, Prochiantz A (1996) Cell internalization of the third helix of Antennapedia homeodomain is receptor-independent. J Biol Chem 271: 18188-18193.6.

Elliott G, O'Hare P (1997) Intracellular trafficking and protein delivery by a herpes virus structure protein. Cell 88:223-233.

English JD, Sweatt JD (1996) Activation of p42 mitogen-activated protein kinase in hippocampal long-term potentiation. J Biol Chem 271:24329-24332.

Ferraguti F, Baldani-Guerra B, Corsi M, Nakanishi S, Corti C (1999) Activation of the extracellular signal-regulated kinase 2 by metabotropic glutamate receptors. Eur J Neurosci 11:2073-2082.

Frankel AD, Pabo CO (1988) Cellular uptake of the tat protein from human immunodeficiency virus. Cell 55:1189-1193.

Frey U, Huang YY, Kandel ER (1993) Effects of cAMP simulate a late stage of LTP in hippocampal CA1 neurons. Science 260:1661-1664.

Gonzalez GA, Montminy MR (1989) Cyclic AMP stimulates somatostatin gene transcription by phosphorylation of CREB at serine 133. Cell 59:675-680.

Green G, Loewenstein PM (1988) Autonoumous functional domains of chemically synthesized human immunodeficiency virus tat transactivator protein. Cell 55:1179-1188.

Greengard P, Valtorta F, Czernik AJ, Benfenati F (1993) Synaptic vesicle phosphoproteins and regulation of synaptic function. Science 259:780-785.

Huang YY, Kandel ER (1994) Recruitment of long-lasting and protein kinase A-dependent long-term potentiation in the CA1 region of hippocampus requires repeated tetanization. Learn Mem 1:74-82.

Impey S, Obrietan K, Wong ST, Poser S, Yano S, Wayman G, Deloulme JC, Chan G, Storm DR (1998) Cross talk between ERK and PKA is required for $\mathrm{Ca}^{2+}$ stimulation of CREB-dependent transcription and ERK nuclear translocation. Neuron 21:869-883.

Kameyama K, Lee HK, Bear MF, Huganir RL (1998) Involvement of a postsynaptic protein kinase A substrate in the expression of homosynaptic long-term depression. Neuron 21:1163-1175.

Katoh-Semba R, Oohira A, Kashiwamata S (1990) Changes in glycosaminoglycans during the neuritogenesis in PC12 pheochromocytoma cells induced by nerve growth factor. J Neurochem 55:1749-1757.

Kemp BE, Cheng HC, Walsh DA (1988) Peptide inhibitors of cAMPdependent protein kinase. Methods Enzymol 159:173-183.

Lindgren M, Hällbrink M, Prochiantz A, Langel Ü (2000) Cellpenetrating peptides. Trends Pharmacol Sci 21:99-103.

Lu YF, Kandel ER, Hawkins RD (1999a) Nitric oxide signaling contributes to late-phase LTP and CREB phosphorylation in the hippocampus. J Neurosci 19:10250-10261.

Lu YF, Kojima N, Tomizawa K, Moriwaki A, Matsushita M, Obata K, Matsui H (1999b) Enhanced synaptic transmission and reduced threshold for LTP induction in fyn-transgenic mice. Eur J Neurosci 11:75-82.

Matsushita M, Nairn AC (1998) Characterization of the mechanism of regulation of $\mathrm{Ca}^{2+} /$ calmodulin-dependent protein kinase I by calmodulin and by $\mathrm{Ca}^{2+} /$ calmodulin-dependent protein kinase kinase. J Biol Chem 273:21473-21481.

Nagahara H, Vocero-Akbani AM, Snyder EL, Ho A, Latham DG, Lissy NA, Becker-Hapak M, Ezhevsky SA, Dowdy SF (1998) Transduction of full-length TAT fusion proteins into mammalian cells: TAT-p-27 Kip1 induces cell migration. Nat Med 4:1449-1452.

Rothbard JB, Garlington S, Lin Q, Kirschberg T, Kreider E, McGrane PL, Wender PA, Khavari PA (2000) Conjugation of arginine oli- 
gomers to cyclosporin A facilitates topical delivery and inhibition of inflammation. Nat Med 6:1253-1257.

Schwarze S, Dowdy SF (2000) In vivo protein transduction: intracellular delivery of biologically active proteins, compounds and DNA. Trends Pharmacol Sci: $21: 45-48$.

Schwarze SR, Ho A, Vocero-Akbani AM, Dowdy SF (1999) In vivo protein transduction: delivery of a biologically active protein into the mouse. Science 285:1569-1572.

Shenolikar S, Nairn AC (1991) Protein phosphatase: recent progress. Adv Second Messenger Phosphoprotein Res 23:1-121.

Steven CF, Sullivan J (1998) Synaptic plasticity. Curr Biol 8:151-153.

Thoren PE, Persson D, Karlsson M, Norden B (2000) The antennapedia peptide penetratin translocates across lipid bilayers: the first direct observation. FEBS Lett 482:265-268.

Tyagi M, Rusnati M, Presta M, Giacca M (2001) Internalization of HIV-1 Tat requires cell surface heparan sulfate proteoglycans. J Biol Chem 276:3254-3261.

Xing J, Ginty DD, Greenberg ME (1996) Coupling of the RAS-MAPK pathway to gene activation by RSK2, a growth factor-regulated CREB kinase. Science 273:959-963.

Yan Z, Hsieh-Wilson L, Feng J, Tomizawa K, Allen PB, Fienberg AA, Nairn AC, Greengard P (2000) Protein phosphatase 1 modulation of neostriatal AMPA channels: regulation by DARPP-32 and spinophilin. Nat Neurosci 2:13-17. 